\title{
Foreign Bodies Injuries in Children in Argentina: A Countrywide Program Connecting Evidence with Prevention
}

\author{
Hugo Rodriguez ${ }^{1, \S}$, Giselle Cuestas ${ }^{1}$, Simonetta Ballali ${ }^{2}$, Graciela Sica ${ }^{3}$, Walter Widmann ${ }^{4}$, \\ Silvina Carca ${ }^{4}$, Susana Tortosa ${ }^{4}$ and Dario Gregori ${ }^{*}, 5, \S$ \\ ${ }^{I}$ Respiratory Endoscopy. Hospital de Pediatria Prof. Juan. P. Garrahan, CABA Buenos Aires, Argentina \\ ${ }^{2}$ Prochild ONLUS, Trieste, Italy \\ ${ }^{3}$ Respiratory Endoscopy. Hospital de Ninos Dr. Ricardo Gutierrez, CABA Buenos Aires, Argentina \\ ${ }^{4}$ Respiratory Endoscopy. Hospital de Ninos Dr. Orlando Alassia, Santa Fe, Argentina \\ ${ }^{5}$ Labs of Epidemiological Methods and Biostatistics, Department of Environmental Medicine and Public Health, \\ University of Padova, Padova, Italy
}

\begin{abstract}
The present study presents 441 cases of foreign bodies (FB) injuries collected in Argentina, in the framework of the Susy safe program, a web-based surveillance registry for foreign body injuries in children aged $0-14$. The analysis was carried out on hospital cases recorded for foreign bodies' injuries, registered in the Susy Safe database and validated as proper for quality and consistency of data.

The current analysis is carried out on FBs located in ears, nose, pharynx and larynx, trachea, bronchi and lungs, mouth, oesophagus and stomach. Injuries occurred most frequently in children older than 3 years Four-hundred-forty-four cases were treated: female patient's incidence was lower than males' one, with a 1:1.24 proportion (44.7\% of female, and $55.3 \%$ males).

Analyzing the outcomes, hospitalization was required in 218 cases $(49.5 \%)$, most frequently when the injury occurred in trachea, bronchi and lungs (36.4\%).

Complications were recorded in 49 patients (11.1\%), the majority of which (5.7\%) presented to the ENT departments with a FB in the respiratory system.

An adult was present in $77.8 \%$ of the cases testifying that primary prevention has a key role in avoiding those kinds of injuries. Particularly, active strategies that promote behavior change seem to be necessary. A communication initiative is under development in Argentina, aimed at informing parents and supervisors of the risks posed by common objects to their children's health.
\end{abstract}

Keywords: Foreign bodies aspiration/ingestion/insertion/inhalation, primary prevention.

\section{INTRODUCTION}

The definition of foreign bodies' injuries comprises all injuries due to ingestion, inhalation, insertion and aspiration of an object into the aero digestive tract $[1,2]$ and in the ears [3]. Since the rapid management is one of the main goals in the presence of such injuries, broadening the information on FBs injuries features like shape, dimension, consistency is fundamental in determining the damage that might occur. Complex relationships among objects, children, and environment concur in determining the dynamic of the asphyxiation and consequently the seriousness of clinical presentation. Particularly, size, shape, type and site of

*Address correspondence to this author at the Labs of Epidemiological Methods and Biostatistics, Department of Environmental Medicine and Public Health, University of Padova, Via Loredan 18, 35131 Padova, Italy; Tel: +39 049 8275384; Fax: +39 02 700445089;

E-mail: dario.gregori@unipd.it

${ }^{\S}$ Hugo Rodriguez and Dario Gregori are Guest Editors for the issue. lodging of the FB are responsible of an important variability on clinical picture: objects causing obstruction in the larynx and trachea are in fact potentially lifethreatening, while objects lodged more distally are frequently undiagnosed and retained and could cause severe complications including pneumonia, atelectasis and bronchiectasis $[4,5]$. Therefore, in order to understand the pathogenetic pathway and to disseminate knowledge in scientific community about this issue, the possibility to know details regarding object characteristics and traumatic event dynamics play a key role. The spectrum of airway foreign bodies usually varies from country to country, depending on the diet and customs of the population; this observation suggests the opportunity to compare and share information coming from different geographical areas.

The need of an improvement of knowledge [6] led to the development of the several projects in Europe, like the ESFBI study [7] or the Susy Safe Project [8]. Indeed, this issue received the attention of the public health authorities funding in Europe the Susy Safe registry [8] of foreign 
bodies injuries, aimed at understanding and preventing such injuries.

The Susy Safe project, which has nowadays ended its Phase II, has reached a sample size of 17000 cases, expanding its boundaries from Europe to new partnerships, like South Africa and South America [9].

The present study presents 441 new cases collected in Argentina, in the framework of the Susy safe program which guarantees a ready-to-use data collection platform, and a common standard in data collection improving the communicability of results abroad and within the country.

\section{MATERIALS AND METHODS}

\section{Sample}

New cases of FB injuries in the aerodigestive tract in paediatric patients 1-14 years old, observed in the Respiratory Endoscopy Unit, Hospital de Pediatria Prof. Juan. P. Garrahan, CABA Buenos Aires, in the Respiratory Endoscopy Unity, Hospital de Ninos Dr. Ricardo Gutierrez, CABA Buenos Aires, and in the Respiratory Endoscopy Unit, Hospital de Ninos Dr. Orlando Alassia, Santa Fe, were added to the Susy Safe database. The main referent in each Hospital was an ENT doctor, cooperating in collecting data with other specialized structures (paediatric, emergency units and gastroenterology). The current analysis is carried out on FBs located in ears, nose, pharynx and larynx, trachea, bronchi and lungs, mouth, oesophagus and stomach.

\section{Statistical Methods}

The analysis was carried out on hospital cases recorded for foreign body injuries, registered in the Susy Safe database and validated as proper for quality and consistency of data. Descriptive statistics about the age and the gender of injured children were worked out. Data regarding adult supervision were also evaluated.
FB location was reported according to ICD9-CM code: ears (ICD931), nose (ICD932), pharynx and larynx (ICD933) trachea, bronchi and lungs (ICD934), mouth, oesophagus and stomach (ICD935).

FB features distribution by children class age, sex and site of obstruction were assessed.

Two different outcomes were considered: complications and hospitalization. These two variables were defined as following: taking for complications all the pathological conditions due to delayed diagnosis or to the attempts of removing the FB. Hospitalization has been considered whether the child was admitted in the hospital for at least 1 day. Odds ratios for FB locations were computed.

Analyses were performed using Design and Hmisc libraries from $\mathrm{R}$ version 2.8 [10].

\section{RESULTS}

Out of the 441 observed cases, female patient's incidence was lower than males' one, with a $1: 1.24$ proportion $(44.7 \%$ of female, and $55.3 \%$ males).

Injuries occurred most frequently in children older than 3 years. All frequencies regarding the age and sex distribution are resumed in Table 1and Fig. (1).

Table 1. Foreign Bodies Injuries Distribution by Age and Gender

\begin{tabular}{|c|c|c|c|c|c|c|}
\hline \multirow{2}{*}{ Age Groups } & \multicolumn{2}{|c|}{ Female } & \multicolumn{2}{c|}{ Male } & \multicolumn{2}{c|}{ Total } \\
\cline { 2 - 7 } & $\mathbf{N}$ & $\%$ & $\mathbf{N}$ & $\%$ & $\mathbf{N}$ & $\%$ \\
\hline \hline$(0-1)$ yrs & 9 & $2.0 \%$ & 5 & $1.1 \%$ & 14 & $3.1 \%$ \\
\hline$(1-3)$ yrs & 86 & $19.4 \%$ & 98 & $22.1 \%$ & 184 & $41.5 \%$ \\
\hline$(3-14)$ yrs & 103 & $23.3 \%$ & 142 & $32.1 \%$ & 245 & $55 . \%$ \\
\hline Total & 198 & $44.7 \%$ & 245 & $55.3 \%$ & 443 & $100.0 \%$ \\
\hline
\end{tabular}

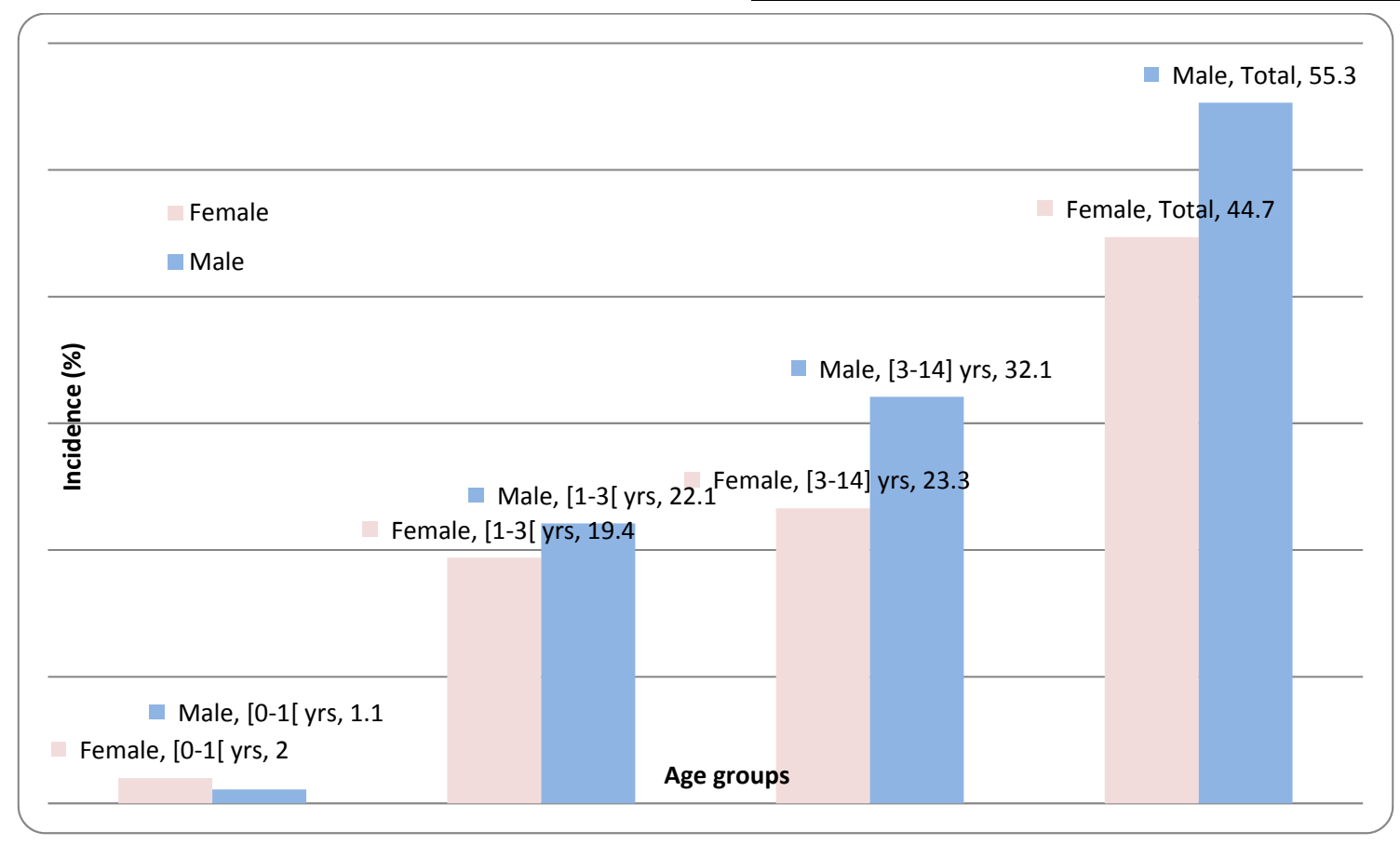

Fig. (1). Age distribution of FBs' injuries. 
The distribution of injuries according to the retrieval location showed a higher incidence in the trachea, bronchi and lungs ( $56 \%$ of cases), followed by mouth, oesophagus and stomach (25.4\% of cases). ICD931 (ears) were recorded in $4.1 \%$ of cases, ICD932 (nose) in $5.2 \%$ and ICD933 (pharynx and larynx) in $7.0 \%$ of cases.

Retrieved FBs varied according to their anatomical location, with nuts and seeds having a incidence of $39.6 \%$ of all tracheobronchial cases; $22.2 \%$ of FBs in the ears were paper FBs; stationery objects(broken pen, cap of pen, eraser for examples) were retrieved in $21.7 \%$ of injuries with FB localized in the nose; bones were retrieved in $25.8 \%$ of pharynx and larynx cases; finallycoins were the most frequent FB in the digestive system (45.5\%). For a broaden description of FBs retrieved in each location, refer to Table 2a-e.

Table 2. Detailed Description of FB's Location

a) Ears

\begin{tabular}{|c|c|c|}
\hline \multicolumn{3}{|c|}{ Ears } \\
\hline FB Type & $\mathbf{N}$ & $\%$ \\
\hline \hline Paper & 4 & $22.2 \%$ \\
\hline Packaging & 3 & $16.7 \%$ \\
\hline Bean & 2 & $11.1 \%$ \\
\hline Plastic & 2 & $11.1 \%$ \\
\hline Stationery & 2 & $11.1 \%$ \\
\hline Candy & 1 & $5.6 \%$ \\
\hline Cloth & 1 & $5.6 \%$ \\
\hline Cotton & 1 & $5.6 \%$ \\
\hline Pearl & 1 & $5.6 \%$ \\
\hline Toy & 1 & $5.6 \%$ \\
\hline Total & 18 & $100.0 \%$ \\
\hline
\end{tabular}

b) Nose

\begin{tabular}{|c|c|c|}
\hline \multicolumn{3}{|c|}{ Nose } \\
\hline FB Type & N & $\%$ \\
\hline \hline Stationery & 5 & $21.7 \%$ \\
\hline Paper & 4 & $17.4 \%$ \\
\hline Battery & 3 & $13.0 \%$ \\
\hline Nuts, seeds and peanuts & 3 & $13.0 \%$ \\
\hline Ball & 1 & $4.3 \%$ \\
\hline Candy & 1 & $4.3 \%$ \\
\hline Cloth & 1 & $4.3 \%$ \\
\hline Food & 1 & $4.3 \%$ \\
\hline Jewellery & 1 & $4.3 \%$ \\
\hline Metal & 1 & $4.3 \%$ \\
\hline Other inorganic & 1 & $4.3 \%$ \\
\hline Pearl & 1 & $4.3 \%$ \\
\hline Total & 23 & $100.0 \%$ \\
\hline
\end{tabular}

(Table 2) contd.....

c) Pharynx and Larynx

\begin{tabular}{|c|c|c|}
\hline \multicolumn{2}{|c|}{ Pharynx and Larynx } \\
\hline FB Type & N & $\%$ \\
\hline Bone & 8 & $25.8 \%$ \\
\hline Food & 5 & $16.1 \%$ \\
\hline Shell & 3 & $9.7 \%$ \\
\hline Metal & 2 & $6.5 \%$ \\
\hline Pin and needle & 2 & $6.5 \%$ \\
\hline Toy & 2 & $6.5 \%$ \\
\hline Ball & 1 & $3.2 \%$ \\
\hline Jewellery & 1 & $3.2 \%$ \\
\hline Missing & 1 & $3.2 \%$ \\
\hline Nuts, seeds and peanuts & 1 & $3.2 \%$ \\
\hline Other inorganic & 1 & $3.2 \%$ \\
\hline Other organic & 1 & $3.2 \%$ \\
\hline Packaging & 1 & $3.2 \%$ \\
\hline Plastic & 1 & $3.2 \%$ \\
\hline Stationery & 1 & $3.2 \%$ \\
\hline Total & 31 & $100.0 \%$ \\
\hline
\end{tabular}

d) Trachea, Bronchi and Lungs

\begin{tabular}{|c|c|c|}
\hline \multicolumn{3}{|c|}{ Trachea, Bronchi and Lungs } \\
\hline FB Type & $\mathbf{N}$ & $\%$ \\
\hline Nuts, seeds and peanuts & 97 & $39.6 \%$ \\
\hline Corn & 28 & $11.4 \%$ \\
\hline Stationery & 22 & $9.0 \%$ \\
\hline Pin and needle & 15 & $6.1 \%$ \\
\hline Food & 11 & $4.5 \%$ \\
\hline Plastic & 10 & $4.1 \%$ \\
\hline Metal & 9 & $3.7 \%$ \\
\hline Ball & 8 & $3.3 \%$ \\
\hline Jewellery & 7 & $2.9 \%$ \\
\hline Toy & 7 & $2.9 \%$ \\
\hline Other organic & 5 & $2.0 \%$ \\
\hline Bean & 4 & $1.6 \%$ \\
\hline Screw & 4 & $1.6 \%$ \\
\hline Bone & 3 & $1.2 \%$ \\
\hline Teeth & 3 & $1.2 \%$ \\
\hline Cloth & 2 & $0.8 \%$ \\
\hline Pearl & 2 & $0.8 \%$ \\
\hline Pebble & 2 & $0.8 \%$ \\
\hline Candy & 1 & $0.4 \%$ \\
\hline Coin & 1 & $0.4 \%$ \\
\hline Grain & 1 & $0.4 \%$ \\
\hline Legumes & 1 & $0.4 \%$ \\
\hline Stone & 1 & $0.4 \%$ \\
\hline Wood & 1 & $0.4 \%$ \\
\hline Total & 245 & $100.0 \%$ \\
\hline
\end{tabular}


(Table 2) contd.....

e) Mouth, Oesophagus and Stomach

\begin{tabular}{|c|c|c|}
\hline \multicolumn{3}{|c|}{ Mouth, Oesophagus and Stomach } \\
\hline FB Type & $\mathbf{N}$ & $\%$ \\
\hline Coin & 55 & $45.5 \%$ \\
\hline Food & 19 & $15.7 \%$ \\
\hline Battery & 14 & $11.6 \%$ \\
\hline Pin and needle & 8 & $6.6 \%$ \\
\hline Metal & 6 & $5.0 \%$ \\
\hline Bone & 4 & $3.3 \%$ \\
\hline Button & 3 & $2.5 \%$ \\
\hline Cloth & 2 & $1.7 \%$ \\
\hline Bean & 1 & $0.8 \%$ \\
\hline Foam & 1 & $0.8 \%$ \\
\hline Jewellery & 1 & $0.8 \%$ \\
\hline Nuts, seeds and peanuts & 1 & $0.8 \%$ \\
\hline Other inorganic & 1 & $0.8 \%$ \\
\hline Packaging & 1 & $0.8 \%$ \\
\hline Paper & 1 & $0.8 \%$ \\
\hline Plastic & 1 & $0.8 \%$ \\
\hline Sponge & 1 & $0.8 \%$ \\
\hline Wood & 1 & $0.8 \%$ \\
\hline Total & 121 & $100.0 \%$ \\
\hline
\end{tabular}

The foreign bodies retrieved were described by macrocategories, stratified by gender, in Table 3 . Argentinean case series showed the highest incidence of injuries due to nuts and seeds $(23.3 \%)$ in both sexes, slightly more frequent in males $(53.9 \%)$ than females $(46.1 \%)$, followed by coins $(12.8 \%)$ and food $(8.2 \%)$. In this study, food category includes all non-specific food types, like pieces of fruits, meat, vegetables.

The activity played by the child at the moment of the accident, was specified in $85 \%$ (377) of cases. The majority of children were playing when the accident occurred (52.5\%) with a similar incidence in females and males, respectively $20.7 \%$ and $21 \%$ of all cases. Data on the activity concomitant to the injuries are shown in Table 4.

An adult was present in $77.8 \%$ of the cases, with a slightly higher incidence when dealing with males $(42.1 \%$ of cases), as presented in Table $\mathbf{5}$.

Analyzing the outcomes, 218 injuries (49.5\%) required hospitalization. Hospitalization was more frequently if the injury occurred in trachea, bronchi and lungs (36.4\%), even if not statisticallysignificant (OR: 1.11, IC95\%: 0.66; 1.85). A full description of the hospitalization cases, stratified by location, is given in Table 6.

Complications were recorded in 49 patients $(11.1 \%)$, the majority of which $(5.7 \%)$ presented to the ENT departments with a FB in the respiratory system. Specific data on complications stratified by location are given in Table 6 . Injuries occurred in trachea, bronchi and lungs had a significant reduced risk of complications (OR: 0.53, IC95\%: $0.39 ; 0.73$ ) with respect to injuries occurred in the digestive system; whereas despite the fact the FB's localized in the nose represent only $5.2 \%$ of injuries, they showed a significant increased risk of complications (OR: 21.6, IC95\%: 2.88;161.68).

Complications were more frequent among males (30 cases, $61.2 \%$ )and in children from 1 to 3 years old (28 cases, $57.1 \%$ ), referred most frequently to unspecified complications requiring further treatments $(22.4 \%)$ followed by erosion, pneumonia and respiratory distress $(12.5 \%$ each category). A detailed description of complications, stratified by age group, is given in Table 7 .

\section{DISCUSSION}

Foreign bodies are a frequent cause of injuries in children, occurring in our study mostly in children older than 3 years and with a similar incidence among the two sexes, both in incidence and context of occurrence.

Analyzing more closely the nature of foreign bodies retrieved, there's a clear dominance of organic objects: seeds were the most frequent $\mathrm{FB}$ in our findings. Reviewing literature on injuries due to nuts and seeds shows similar results to this study $[11,12]$. All results stress that, mostly in young children, there's a high risk for aspirating fragments of organic parts due to their not yet accomplished chewing's capacity. In addition to the occurrence risk, bronchoscopic removal sometimes becomes very difficult and frequently more than one attempt is needed because nuts break into amorphous and hard pieces [13].

The most staggering retrieval in our analysis is the high frequency of adult's presence while the injuries happened. In $77.8 \%$ of all cases an adult was with the child who incurred in the accident, that in most cases was either playing or eating. These data not only point towards a worrying common trend in different countries [14-16] but also show how primary prevention in Argentina is still lacking an impact, towards an event that is not common as other injuries, like road traffic injuries that accounted for the $0.2 \%$ of all estimated deaths in 2008 among children 0-14 in Argentina [17] but that might end more frequently in fatalities, especially when affecting the tracheobronchial tree as in our study [18].

Primary prevention is therefore seen as a key to avoid those kind of injuries. Particularly, active strategies that promote behavior change are necessary. Active strategies require that a care giver changes his or her behavior each time the child begins an activity that has the potential to cause injury. Education is critical to these active strategies and plays a complementary role to environmental changes and legal mandates [19] and information about safe behaviors should be included in all visits to paediatricians in order to make parents able to be recognize potentially dangerous products, identify risky situations and better control children access to hazardous objects. An initiative, based on a poster, aimed at being displayed in Hospital and Schools has been developed as a product of this joint initiative (Fig. 2). The poster is targeted to parents and adult supervisors, to make them aware of the risks posed by common objects in terms of chocking, ingestion or insertion in upper orifices to their children. 
Table 3. Distribution of Foreign Bodies Type According to Gender

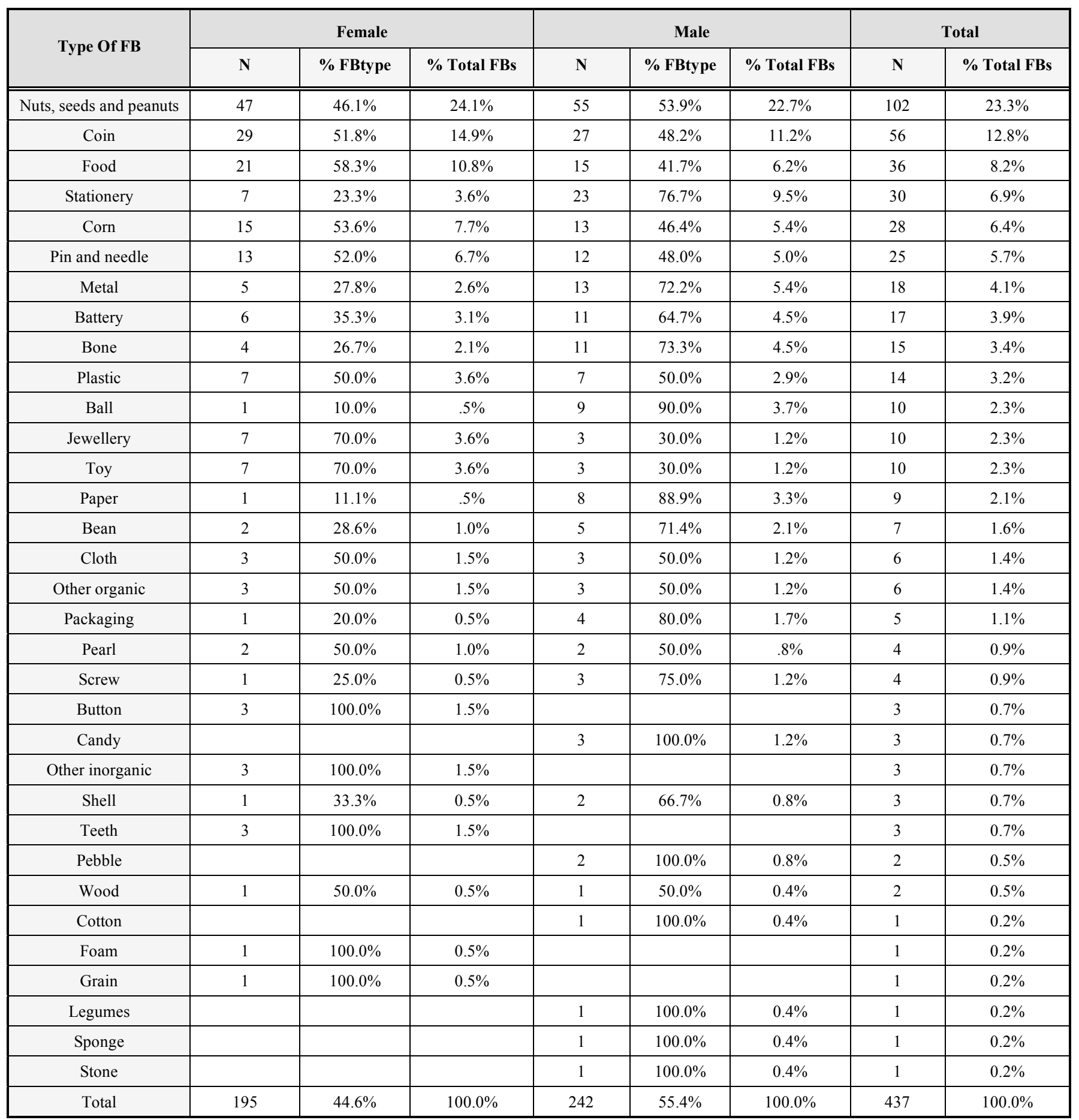

Table 4. Activity Performed when the Accident Occurred

\begin{tabular}{|c|c|c|c|c|c|c|}
\hline \multirow{2}{*}{ Activity Performed } & \multicolumn{2}{|c|}{ Female } & \multicolumn{2}{c|}{ Male } & \multicolumn{2}{c|}{ Total } \\
\cline { 2 - 7 } & $\mathbf{N}$ & $\%$ & $\mathbf{N}$ & $\%$ & $\mathbf{N}$ & $\%$ \\
\hline \hline Playing & 93 & $24.7 \%$ & 105 & $27.9 \%$ & 198 & $52.5 \%$ \\
\hline Eating & 78 & $20.7 \%$ & 79 & $21.0 \%$ & 157 & $41.6 \%$ \\
\hline Other & 4 & $1.1 \%$ & 18 & $4.8 \%$ & 22 & $5.8 \%$ \\
\hline Total & 175 & $46.4 \%$ & 202 & $53.6 \%$ & 377 & $100.0 \%$ \\
\hline
\end{tabular}

Table 5. Adult Presence when the Accident Occurred

\begin{tabular}{|c|c|c|c|c|c|c|}
\hline \multirow{2}{*}{ Adult Presence } & \multicolumn{2}{|c|}{ Female } & \multicolumn{2}{c|}{ Male } & \multicolumn{2}{c|}{ Total } \\
\cline { 2 - 7 } & $\mathbf{N}$ & $\%$ & $\mathbf{N}$ & $\%$ & $\mathbf{N}$ & $\%$ \\
\hline \hline No & 40 & $9.2 \%$ & 57 & $13.0 \%$ & 97 & $22.2 \%$ \\
\hline Yes & 156 & $35.7 \%$ & 184 & $42.1 \%$ & 340 & $77.8 \%$ \\
\hline Total & 196 & $44.9 \%$ & 241 & $55.1 \%$ & 437 & $100.0 \%$ \\
\hline
\end{tabular}


Table 6. Hospitalization and Complications Stratified by Location's Retrieval

\begin{tabular}{|c|c|c|c|c|c|c|}
\hline & \multicolumn{3}{|c|}{ Hospitalization } & \multicolumn{3}{|c|}{ Complications } \\
\hline & No & Yes & OR (IC95\%) & No & Yes & OR (IC95\%) \\
\hline \multirow{2}{*}{ Ears } & 18 & 0 & \multirow{2}{*}{ NS } & 18 & 0 & \multirow{2}{*}{ NS } \\
\hline & $8.10 \%$ & $0.00 \%$ & & $4.10 \%$ & $0 \%$ & \\
\hline \multirow{2}{*}{ Nose } & 22 & 1 & \multirow{2}{*}{$0.59(0.19 ; 1.82)$} & 19 & 4 & \multirow{2}{*}{$21.6(2.88 ; 161.68)$} \\
\hline & $5.00 \%$ & $0.20 \%$ & & $4.30 \%$ & $0.90 \%$ & \\
\hline \multirow{2}{*}{ Pharynx and larynx } & 20 & 11 & \multirow{2}{*}{$0.84(0.28 ; 2.51)$} & 27 & 4 & \multirow{2}{*}{$1.78(0.83 ; 3.81)$} \\
\hline & $4.50 \%$ & $2.50 \%$ & & $6.10 \%$ & $0.90 \%$ & \\
\hline \multirow{2}{*}{ Trachea, bronchi and lungs } & 87 & 160 & \multirow{2}{*}{$1.11(0.66 ; 1.85)$} & 222 & 25 & \multirow{2}{*}{$0.53(0.39 ; 0.73)$} \\
\hline & $19.80 \%$ & $36.40 \%$ & & $50.30 \%$ & $5.70 \%$ & \\
\hline \multirow{2}{*}{ Mouth, oesophagus and stomach } & 75 & 46 & \multirow{2}{*}{ Ref } & 106 & 16 & \multirow{2}{*}{ Ref } \\
\hline & $17.00 \%$ & $10.50 \%$ & & $24.00 \%$ & $3.60 \%$ & \\
\hline \multirow{2}{*}{ Total } & 222 & 218 & & 392 & 49 & \\
\hline & $50.50 \%$ & $49.50 \%$ & & $88.90 \%$ & $11.10 \%$ & \\
\hline
\end{tabular}

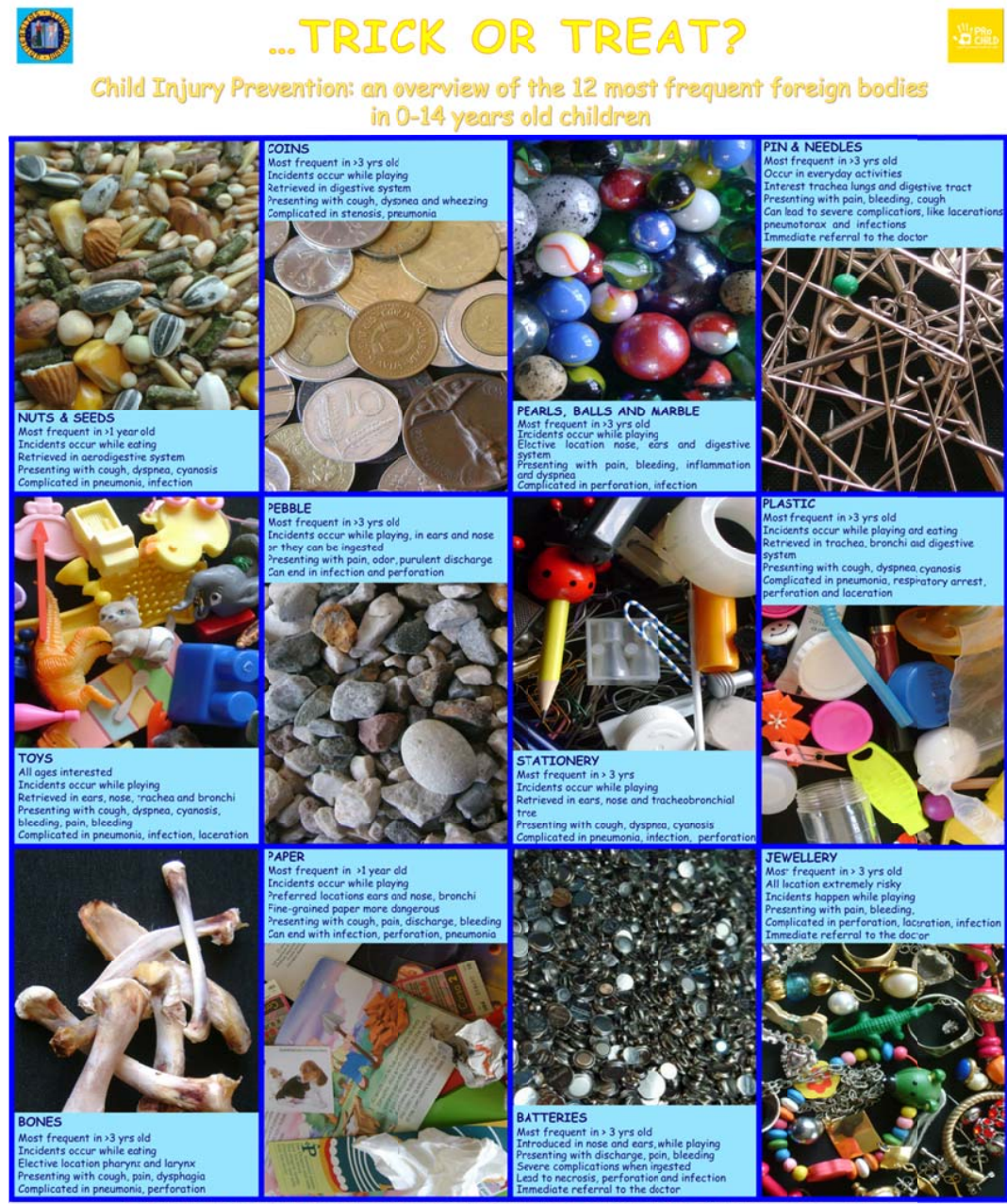

INJURIES DUE TO FOREIGN BODIES CAN END IN FATALITIES, $70 \%$ OF INCIDENTS HAPPEN WHILE THE CHILD IS WITH AN ADULT ACTIVE SUPERVISTON IS THE KEY TO PREVENTION

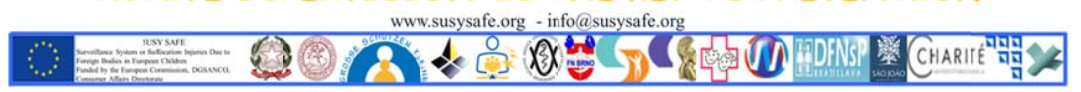

Fig. (2). The general version of the poster ment for advising parents and supervisors of the risks posed by common objects in terms of choking, ingestion or insertion in the upper orifices. Localized versions of the poster can be downloaded from the website www.susysafe.org. 
Table 7. Detailed Complications Stratified by Age Groups

\begin{tabular}{|c|c|c|c|c|c|}
\hline \multirow{2}{*}{ Detailed Complication } & {$[\mathbf{0}-1]$ yrs } & {$[1-3]$ yrs } & {$[3-14]$ yrs } & \multicolumn{2}{|c|}{ Total } \\
\cline { 2 - 6 } & $\mathbf{N}$ & $\mathbf{N}$ & $\mathbf{N}$ & $\mathbf{N}$ & $\%$ \\
\hline \hline Unspecified & & 5 & 6 & 11 & $22.4 \%$ \\
\hline Erosion & & 4 & 2 & 6 & $12.2 \%$ \\
\hline Pneumonia & & 3 & 3 & 6 & $12.2 \%$ \\
\hline Respiratory distress & & 3 & 3 & 6 & $12.2 \%$ \\
\hline Infection & 1 & 3 & 1 & 5 & $10.2 \%$ \\
\hline No complic & & 2 & 2 & 4 & $8.2 \%$ \\
\hline Abscess & & 2 & & 2 & $4.1 \%$ \\
\hline Bleeding & & 1 & 1 & 2 & $4.1 \%$ \\
\hline Necrosis & & 1 & 1 & 2 & $4.1 \%$ \\
\hline Atelectasis & & 1 & & 1 & $2.0 \%$ \\
\hline Edema & & 1 & & 1 & $2.0 \%$ \\
\hline Fistula & & 1 & & 1 & $2.0 \%$ \\
\hline Laceration & & & 1 & 1 & $2.0 \%$ \\
\hline Perforation & & 1 & & 1 & $2.0 \%$ \\
\hline Total & 1 & 28 & 20 & 49 & $100.0 \%$ \\
\hline
\end{tabular}

\section{ACKNOWLEDGEMENT}

None declared.

\section{CONFLICT OF INTEREST}

None declared.

\section{REFERENCES}

[1] Brkic F, Umihanic S. Tracheobronchial foreign bodies in children. Experience at ORL clinic Tuzla, 1954-2004. Int J Pediatr Otorhinolaryngol 2007;71(6): 909-15.

[2] Gregori D, Scarinzi C, Morra B, et al. Ingested foreign bodies causing complications and requiring hospitalization in European children: results from the ESFBI study. Pediatr Int 2010 ; 52(1):2632.
[3] Balbani AP, Sanchez TG, Butugan O, et al. Ear and nose foreign body removal in children. Int J Pediatr Otorhinolaryngol 1998;46 (1-2): 37-42.

[4] Robinson PJ. Laryngeal foreign bodies in children: first stop before the right main bronchus. J Paediatr Child Health 2003; 39 (6): 4779.

[5] Sirmali M, Turut H, Kisacik E, et al. The relationship between time of admittance and complications in paediatric tracheobronchial foreign body aspiration. Acta Chir Belg 2005;105(6):631-4.

[6] Gregori D, Foltran F, Passali D. Foreign body injuries in children: need for a step forward against an old yet neglected epidemic. Paediatr Perinat Epidemiol 2011;25(2): 98-9.

[7] Gregori D, Salerni L, Scarinzi C, et al. Foreign bodies in the upper airways causing complications and requiring hospitalization in children aged 0-14 years: results from the ESFBI study. Eur Arch Otorhinolaryngol $2008 ; 265(8): 971-8$.

[8] Gregori D. The Susy Safe Project. A web-based registry of foreign bodies injuries in children. Int J Pediatr Otorhinolaryngol $2006 ; 70$ (9): $1663-4$.

[9] Rodriguez H, Chinski A, Gregori D, et al. [The Susy Safe project: an international initiative aimed at preventing choking a caused by foreign bodies in children: invitation to participation]. Arch Argent Pediatr $2010 ; 108(4): 384$.

[10] R Development Core Team. R: A language and environment for statistical computing. 2008.

[11] Altkorn R, Chen X, Milkovich S, et al. Fatal and non-fatal food injuries among children (aged 0-14 years). Int $\mathrm{J}$ Pediatr Otorhinolaryngol $2008 ; 72$ (7):1041-6.

[12] Gregori D, Salerni L, Scarinzi C, et al. Foreign bodies in the nose causing complications and requiring hospitalization in children 0 14 age: results from the European survey of foreign bodies injuries study. Rhinology 2008; 46(1):28-33.

[13] Keith FM, Charrette EJ, Lynn RB, et al. Inhalation of foreign bodies by children: a continuing challege in management. Can Med Assoc J 1980;122(1):52, 5-7.

[14] Chacon FS, Ballali S, Passali D, et al. Epidemiology of foreign bodies injuries in Ecuador: a first look based on a single centre experience. Int J Pediatr Otorhinolaryngol 2011;75(6):854-7.

[15] Endican S, Garap JP, Dubey SP. Ear, nose and throat foreign bodies in Melanesian children: an analysis of 1037 cases. Int J Pediatr Otorhinolaryngol $2006 ; 70(9): 1539-45$.

[16] Paul SP, Hawes D, Taylor TM. Foreign body ingestion in children: case series, review of the literature and guidelines on minimising accidental ingestions. J Fam Health Care 2010; 20(6):200-4.

[17] WHO. The Global Burden of Disease. 2004. Update 2008.

[18] Fraga AM, Fraga GP, Stanley C, Costantini TW, Coimbra R. Children at danger: injury fatalities among children in San Diego County. Eur J Epidemiol 2010; 25(3):211-7.

[19] Deal LW, Gomby DS, Zippiroli L, Behrman RE. Unintentional injuries in childhood: analysis and recommendations. Future Child 2000 Spring-Summer; 10(1):4-22. 